\title{
Universiteit
}

Leiden

The Netherlands

\section{Interictal depression, anxiety, personality traits, and psychological dissociation in patients with temporal lobe epilepsy (TLE) and extra-}

\section{TLE.}

Swinkels, W.A.M.; Emde Boas, W. van; Kuyk, J.; Dyck, R. van; Spinhoven, P.

\section{Citation}

Swinkels, W. A. M., Emde Boas, W. van, Kuyk, J., Dyck, R. van, \& Spinhoven, P. (2006).

Interictal depression, anxiety, personality traits, and psychological dissociation in patients with temporal lobe epilepsy (TLE) and extra- TLE. Epilepsia, 47, 2092-2103.

doi:10.1111/j.1528-1167.2006.00808.x

Version: $\quad$ Not Applicable (or Unknown)

License: $\quad$ Leiden University Non-exclusive license

Downloaded from: https://hdl.handle.net/1887/13191

Note: To cite this publication please use the final published version (if applicable). 


\title{
Interictal Depression, Anxiety, Personality Traits, and Psychological Dissociation in Patients with Temporal Lobe Epilepsy (TLE) and Extra-TLE
}

\author{
*Wilhelmina A.M. Swinkels, †Walter van Emde Boas, *Jarl Kuyk, †Richard van Dyck, \\ and $§$ Philip Spinhoven
}

Departments of ${ }^{*}$ Psychology and $\dagger E E G$ and EMU, Epilepsy Institute of The Netherlands, Heemstede; $\neq$ Department of Psychiatry, Vrije Universiteit Amsterdam, Amsterdam; and §Department of Clinical and Health Psychology and Psychiatry, Leiden University, Leiden, The Netherlands

Summary: Purpose: This study was performed to investigate the relation between symptoms of interictal depression, anxiety, personality traits, and psychological dissociation with the localization and lateralization of the epileptogenic zone in patients with partial epilepsy.

Methods: All patients were diagnosed according to the localization-related concept of the 1989 International League Against Epilepsy (ILAE) Classification of Epilepsies and Epileptic Syndromes, and the localization and lateralization of the epileptogenic zone was established by using the clinical criteria for noninvasive presurgical evaluation. This resulted in $67 \mathrm{pa}-$ tients with temporal lobe epilepsy (TLE) and 64 patients with extra-TLE. All patients were assessed on the various aspects of psychopathology by using a comprehensive battery of standardized diagnostic instruments.
Results: We did not find the hypothesized excess of psychiatric symptoms in patients with (mesial) TLE in comparison with patients with extra-TLE. We also found no differences between patients with the lateralization of epilepsy in the left versus the right hemisphere.

Conclusions: TLE per se cannot be considered a risk factor in developing more or more severe symptoms of psychopathology in patients with partial epilepsy. Concomitant factors, such as the duration of epilepsy, seizure frequency, and frontal lobe dysfunction may play an additional role. Our findings support the hypothesis of a multifactorial explanation for the psychiatric symptoms in patients with epilepsy. Key Words: Epilepsy-Psychiatric disorders-Personality disorders-Temporal lobe epilepsy.
Many studies have noted a higher prevalence of psychiatric morbidity in patients with epilepsy compared with normal controls (Pond and Bidwell, 1959/1960; Zielinski, 1974; Kogeorgos et al., 1982; Whitman et al., 1984; Dodrill and Batzel, 1986; Jalava and Sillanpaa, 1996; Mendez et al., 1986; Ettinger et al., 1998; Swinkels et al., 2001). Reviews of the relevant literature suggest that mood and anxiety disorders are the most frequently diagnosed psychiatric disorders in patients with epilepsy (Betts, 1981; Robertson and Trimble, 1983; Hermann and Whitman, 1984; Hermann et al., 2000). An increased prevalence of personality (disorder) traits or disorders is frequently found in these patients (Bear and Fedio, 1977; Schwartz and Cummings, 1988; Swinkels et al., 2003).

\footnotetext{
Accepted March 3, 2006.

Address correspondence and reprint requests to Dr. W.A.M. Swinkels at Epilepsy Institute of the Netherlands, SEIN, Postbox 540, 2130 AM Hoofddorp, Heemstede, The Netherlands. E-mail: mswinkels@sein.nl doi: $10.1111 / \mathrm{j} .1528-1167.2006 .00808 . x$
}

Traditionally, temporal lobe epilepsy (TLE) is considered to present a relatively specific risk factor, notably for affective disorders, because of the major involvement of the limbic system both in seizure generation in TLE and in the regulation of affect and mood. Numerous studies have reported an increased rate of psychiatric disturbances in patients with TLE, compared with patients with other types of epilepsy (Gibbs et al., 1948; Gibbs, 1951; Pond and Bidwell, 1959/1960; Gudmundsson, 1966; Zielinski, 1974; Rodin et al., 1976; Bear and Fedio, 1977; Shukla et al., 1979; Brown et al., 1986; Mendez et al., 1986; Altshuler et al., 1990; Gureje, 1991; Perini et al. 1996; Quiske et al., 2000). Other studies, however, failed to document such an association between TLE and psychiatric symptoms (Guerrant et al., 1962; Small et al., 1962; Small et al., 1966; Stevens, 1966; Matthews and Klove, 1968; Mignone et al., 1970; Standage and Fenton, 1975; Dikmen et al., 1983; Dodrill and Batzel, 1986; Edeh and Toone, 1987; Robertson et al., 1987; Manchanda et al., 1992; Fiordelli et al., 1993; Manchanda et al., 1995; Swinkels et al., 2001; 
Isaacs et al., 2004; Feddersen et al., 2005). The laterality of the seizure focus has also been considered as a potential risk factor for psychiatric illness in epilepsy. Some authors emphasize the role of the right hemisphere (FlorHenry, 1969; Kohler et al., 1999), which is suggested to have more extensive limbic connections than the left hemisphere, whereas the majority of the studies implicate the left hemisphere (Perini and Mendius, 1984; Mendez et al., 1986; Altshuler et al., 1990; Bromfield et al., 1992; Septien et al., 1993; Mendez et al., 1994; Victoroff et al., 1994), or find no effect of lateralization at all (Mignone et al., 1970; Robertson et al., 1987; Hermann and Wyler, 1989; Hermann et al., 1991; Naugle et al., 1991; Manchanda et al., 1992; Manchanda et al., 1995; Schmitz et al., 1997; Helmstaedter et al., 2004; Feddersen et al., 2005). Although support exists for the association between epilepsy and psychiatric disorders, the empiric evidence for a specific association between the localization and lateralization of the epileptogenic zone in partial epilepsy and psychiatric morbidity remains equivocal.

Both methodologic and theoretical factors appear to account for these discrepant findings. For psychiatric assessment, a variety of diagnostic instruments are used, ranging from predominantly subjective self-reporting questionnaires to objective and reliable diagnostic tests. Some authors use cutoff scores to classify the subjects, whereas others use mean scores. Psychiatric findings from these studies are thus difficult to compare.

The same can be said for the selection of patients with epilepsy who were investigated and the control subjects. Several studies fail to define clear diagnostic criteria for epilepsy and/or psychiatric disorders and their selection criteria, and precise definitions of epilepsy subgroups are often unclear or not provided at all.

Early studies on the prevalence of psychiatric syndromes in epilepsy mostly focused on patients with "psychomotor seizures" (e.g., Gibbs et al., 1948; Small et al., 1962; Stevens, 1966; Matthews and Klove, 1968; Mignone et al., 1970), then thought to represent exclusively TLE. Although these seizures, which are now classified as complex partial seizures (ILAE, 1981), are known to arise frequently from the temporal lobe, they may also originate from extratemporal areas, notably the frontal lobes. Moreover, seizures that do have their onset in the temporal lobe will often invade extratemporal structures in the course of the seizure (Wieser, 1983), and several investigators have suggested that concomitant frontal lobe dysfunction may also play an important role in the association between (left) TLE and psychopathology (Hermann et al., 1991; Bromfield et al., 1992; Schmitz et al., 1997).

This variability in the pathologic anatomy of complex partial seizures seems likely to be in part responsible for the lack of consistent findings across the different studies (Paradiso et al., 1995) and emphasizes the need for more homogeneous patient and control groups. In the studies cited, patient groups were usually limited, and control subjects varied. In most studies, subjects with epilepsy were compared with healthy subjects or with patients with other varying disorders. Comparison of TLE patients with other subjects with epilepsy was rare. Tables 1 and 2 list some of the most commonly cited studies claiming to find an excess of psychiatric comorbidity in TLE patients and in those failing to do so. In the Comments column, the methodologic shortcomings are briefly summarized.

In practice, it is difficult to select truly homogeneous patient groups in partial epilepsy studies because of the multitude of neurobiologic, psychosocial, and iatrogenic factors involved. Apart from the localization, lateralization, and extent of the epileptogenic zone, other variables [e.g., etiology, age at onset/duration of epilepsy, seizure type(s), seizure frequency/severity, antiepileptic medication (AED)] may be of equal importance. Nevertheless, it is usually possible, with the help of careful analysis of the clinical signs and symptoms observed or reported during the seizures, together with state-of-the art EEG, video, and neuroimaging, to classify patients with partial seizures into fairly homogeneous groups, based on the presumed or, in some, documented lobe of seizure onset (ILAE, 1989).

Following the results of previous investigations (Kuyk et al., 1999; Swinkels et al., 2001; Swinkels et al., 2003), this study was designed to assess in more detail the relation between symptoms of interictal depression, anxiety, personality traits, and psychological dissociation with the localization and lateralization of the epileptogenic zone in patients with cryptogenic or symptomatic partial epilepsy. Because earlier studies on the neurobiologic factors of depression demonstrated a significant role of temporomesial limbic structures in depression (Drevets et al., 1992; Grasso et al., 1994; Sabatini et al., 1996; Quiske et al., 2000), we also wanted to assess whether patients with anteromesial TLE showed more psychiatric symptoms (especially depression) compared with patients with laterobasal TLE. To overcome some of the methodologic weaknesses of previous investigations, patients were specifically classified into localization-related syndrome subgroups, which were then compared with each other. Psychiatric comorbidity was assessed by using reliable and valid diagnostic instruments. Finally, other epilepsy-related variables were also evaluated as potential risk factors for psychiatric symptoms and disorders.

\section{METHODS}

\section{Subjects}

Patients were recruited between October 1999 and May 2002 from the clinical observation wards and the outpatient departments of the Epilepsy Institute of the Netherlands (SEIN), a specialized epilepsy center. 


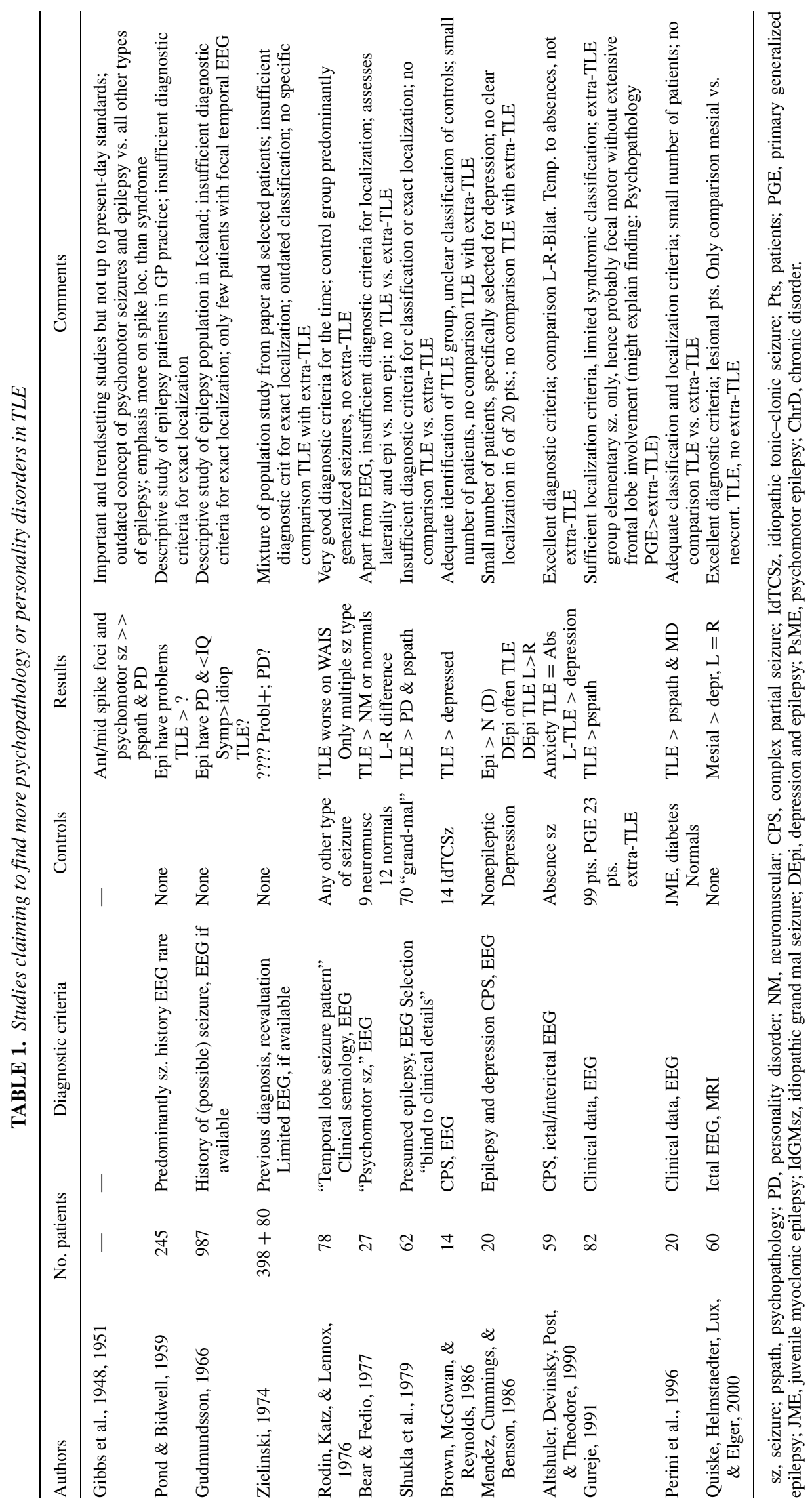




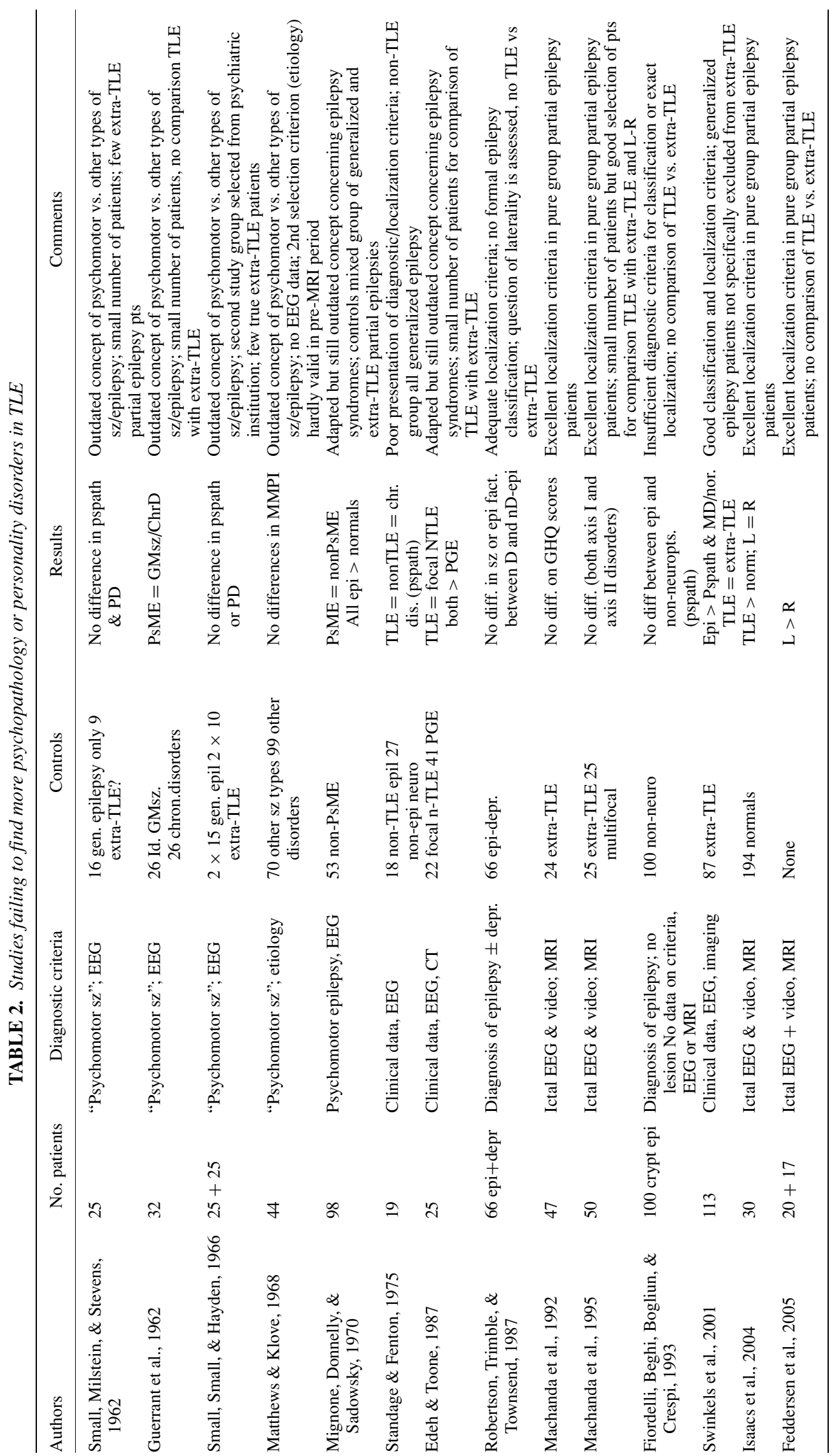


To participate, adult patients of either sex had to have a firm diagnosis of partial (localization-related) epilepsy, unilobar but otherwise independent of etiology, localization, or lateralization of the presumed epileptogenic zone. Patients with active psychogenic pseudoepileptic attacks (PPEAs) were excluded. Patients with other types of epilepsy or with equivocal epilepsy classification were also excluded, as were patients with evidence of concomitant progressive or general medical disease.

Patients were recruited by the treating physicians, and the study's purpose and content was explained. Patients were also provided with written information and informed consent forms.

Because, hypothetically, patients who were admitted for clinical observation could show different or more severe psychiatric comorbidity than the relatively stable outpatients (many of whom visited the outpatient clinic at 6- or 12-month intervals only), we strove to include equal numbers of inpatients and outpatients. In practice, however, the outpatient group proved to be less motivated for study participation than were the inpatients. Only 53 (49.5\%) of the 107 outpatients who received the written information agreed to participate in the study. Thirty-two (29.9\%) patients refused participation (the most common arguments being: "I am fine now and don't want to be bothered by all this"; "I do not want to spend the time necessary for the testing"; or "I had all these tests long ago, at the time of my admission, and do not want to have them again"), and $22(20.6 \%)$ failed to respond. In comparison, 80\% of the inpatients agreed to participate.

Over the 32-month period, 153 potential study participants were recruited. Of these, 22 (including two outpatients) had to be excluded because of either a change of diagnosis to generalized epilepsy $(n=3)$, observation of PPEAs during admission $(n=4)$, or a final diagnosis of either multilobar or equivocally localized partial epilepsy $(\mathrm{n}=15)$. The final study group thus included 131 subjects: 80 inpatients and 51 outpatients. All patients gave their informed consent, and the study was approved by the SEIN Medical Ethics Committee.

An epilepsy diagnosis was formulated for all patients (by W.vE.B.), as if for initial presurgical patient selection, according to the localization-related concept of the 1989 ILAE Classification of the Epilepsies and Epilepsy Syndromes. This was based on all available clinical information (for inpatients reviewed after discharge), neuroimaging (MRI and/or CT available for all patients), and the best available EEG (and video) data: video-EEG seizure recordings $[\mathrm{n}=67(51.1 \%)]$, prolonged videoEEG records without seizures $[\mathrm{n}=10(7.6 \%)]$, or multiple awake and sleep recordings $[n=54(41.2 \%)]$. Lateralization was categorized as right, left, or bilateral when no unequivocal lateralization was possible. For TLE subjects, a differentiation was made between anteromesial TLE and laterobasal TLE, as suggested in the 1989 ILAE classification. This differentiation was based on clinical,
TABLE 3. Localization and lateralization of the patients

\begin{tabular}{lcccc}
\hline $\begin{array}{l}\text { Lateralization } \\
\text { Localization }\end{array}$ & $\begin{array}{c}\text { Left } \\
(\mathrm{n})\end{array}$ & $\begin{array}{c}\text { Right } \\
(\mathrm{n})\end{array}$ & $\begin{array}{c}\text { Bilateral } \\
(\mathrm{n})\end{array}$ & $\begin{array}{c}\text { Total } \\
(\mathrm{n})\end{array}$ \\
\hline MTLE & 13 & 10 & 3 & 26 \\
LTLE & 17 & 6 & 3 & 26 \\
TLE diffuse & 8 & 4 & 3 & 15 \\
Total & 38 & 20 & 9 & 67 \\
Extra-TLE: Frontal $^{a}$ & 27 & 20 & 9 & 56 \\
Extra-TLE: Parietal & 6 & 1 & 0 & 7 \\
Extra-TLE: Occipital & 1 & 0 & 0 & 1 \\
Total & 34 & 21 & 9 & 64 \\
\hline
\end{tabular}

MTLE, temporal lobe epilepsy, predominant anteromesial; LTLE temporal lobe epilepsy, predominantly (posterior)-laterobasal neocortical.

${ }^{a}$ Including the frontal-central area.

imaging, and EEG criteria, as published in the literature (Emde Boas Van and Parra Gomez, 2001), even though more recent studies have shown overlapping electroclinical features in different TLE seizure types (Maillard et al., 2004). Localization and lateralization categories of these 131 patients are shown in Table 3. The clinical characteristics of the patient groups are listed in Table 4.

TABLE 4. Patient characteristics

\begin{tabular}{|c|c|c|c|}
\hline Demographic variables & TLE $(\mathrm{n}=67)$ & $\begin{array}{l}\text { Extra-TLE } \\
(\mathrm{n}=64)\end{array}$ & $\mathrm{p}$ \\
\hline $\operatorname{Sex}(\%)$ & & & 0.01 \\
\hline Male & 38.8 & 64.1 & \\
\hline Female & 61.2 & 35.9 & \\
\hline Age (yr) & & & 0.01 \\
\hline $\mathrm{M}$ & 43.5 & 37.3 & \\
\hline SD & 15.2 & 11.9 & \\
\hline \multicolumn{4}{|l|}{ Education (\%) } \\
\hline Primary & 63.6 & 45.3 & \\
\hline Secondary & 28.8 & 43.8 & \\
\hline Higher & 7.6 & 10.9 & \\
\hline \multicolumn{4}{|l|}{ Civil state (\%) } \\
\hline Married/living together & 50.0 & 48.4 & \\
\hline Single & 50.0 & 51.6 & \\
\hline \multicolumn{4}{|l|}{ Age at onset of epilepsy (yr) } \\
\hline M & 17.4 & 18.3 & \\
\hline SD & 12.6 & 12.8 & \\
\hline Duration of epilepsy (yr) & & & 0.01 \\
\hline $\mathrm{M}$ & 26.0 & 19.0 & \\
\hline SD & 17.1 & 12.2 & \\
\hline Seizure frequency (\%) & & & 0.001 \\
\hline No seizures & 19.6 & 11.3 & \\
\hline Monthly & 37.5 & 45.3 & \\
\hline Weekly & 39.3 & 11.3 & \\
\hline Daily & 3.6 & 32.1 & \\
\hline \multicolumn{4}{|l|}{ Origin of patients (\%) } \\
\hline Inpatients & 55.2 & 67.2 & \\
\hline Outpatients & 44.8 & 32.8 & \\
\hline Lesion & & & 0.05 \\
\hline Yes & 59.7 & 40.3 & \\
\hline No & 25.4 & 46.8 & \\
\hline Unclear & 14.9 & 12.9 & \\
\hline \multicolumn{4}{|l|}{ AEDs } \\
\hline M & 2.27 & 2.28 & \\
\hline SD & 0.99 & 1.05 & \\
\hline
\end{tabular}

M, mean; SD, standard deviation; AEDs, antiepileptic drugs. 


\section{Instruments}

\section{Depression}

Depressive mood was assessed with the Beck Depression Inventory (BDI), a reliable and widely used selfrating questionnaire. The BDI consists of 21 items, with scores that range from 0 to 3 . A score $>12$ is considered to indicate a mild form of depressive mood, and a score $>18$ is regarded as indicative of clinical depression (Beck et al., 1979; Bouman et al., 1985).

Diagnostic and Statistical Manual of Mental Disorders (DSM)-IV Axis I mood disorders were determined by means of the computerized version of the Composite International Diagnostic Interview (CIDI-auto, Dutch version 2.1) (WHO, 1993; Ter Smitten et al., 1997). It is a valid and reliable structured diagnostic interview for use in different settings, cultures, and countries. The prevalence of major depression and dysthymia during the last year was determined.

\section{Anxiety}

The Dutch version of the State-Trait Anxiety Inventory (ZBV: Zelf-Beoordelings Vragenlijst) (Spiegelberger et al., 1970; Van der Ploeg et al., 1980) was used to investigate the current anxiety state and anxiety as a personality trait. Both the ZBV state scale and trait scale consist of 20 items scored on a 4-point Likert scale from 1 (hardly ever) to 4 (almost always).

The CIDI was used to determine the prevalence of DSM-IV anxiety disorders during the last year. The following anxiety disorders were assessed: panic disorder, agoraphobia, simple phobia, social phobia, generalized anxiety disorder, and obsessive compulsive disorder.

\section{Personality inventories}

DSM-IV axis II personality disorder traits were assessed by the Questionnaire on Personality Traits (VKP: Vragenlijst voor Kenmerken van de Persoonlijkheid) (Duijsens et al., 1999). The VKP is a self-report questionnaire, based on the International Personality Disorder Examination (IPDE) (WHO, 1995). It consists of 197 questions scored on a 3-point scale [true (2); ? (1); false (0)]. Twelve questions have a fourth answer possibility, "not applicable" (0). For each personality disorder, a dimensional score and a categoric diagnosis are given. The dimensional score indicates the number of DSM-IV criteria that are confirmed for each personality disorder, and in this way reflects traits of the personality disorder. The categoric diagnosis contains the negative, probable, and positive diagnosis.

The NEO Five-Factor Inventory (Costa and McCrae, 1992; Hoekstra et al., 1996) was used to assess the five domains of personality: neuroticism, extraversion, openness, agreeableness, and conscientiousness. It contains 60 items on a 5-point scale, ranging from "strongly agree" to "strongly disagree."

\section{General psychopathology}

The Symptom Checklist-90 (SCL-90) (Derogatis, 1977; Arrindell and Ettema, 1986) was used to assess the general level of psychopathology. It contains 90 questions about recent somatic and psychological complaints that can be scored on a 5-point scale. The 90 items can be assigned to eight dimensions: anxiety, agoraphobia, depression, somatic complaints, insufficiency, sensitivity, hostility, and sleeping problems. On the basis of these eight subscale scores, a general psychoneuroticism score is given.

The Hospital Anxiety and Depression Scale (HADS) (Spinhoven et al., 1997) was used to indicate the severity of anxiety and depressive states. The HADS contains two seven-item scales: one for anxiety and one for depression, with both a score range of $0-21$. A total score is also given. The HADS is considered to be unbiased by coexisting medical condition (because of the exclusion of items referring to symptoms that may have a physical cause).

\section{Psychological dissociation}

The Dissociation Questionnaire (DIS.Q) (Vanderlinden et al., 1993) is a 63-item, 5-point, self-reporting questionnaire designed to measure psychological dissociation. Apart from a total score, four subscale scores are included: identity confusion and fragmentation (referring to experiences of derealization and depersonalization), loss of control (overt behavior, thoughts, and emotions), amnesia (referring to memory lacunae), and absorption (referring to experiences of enhanced concentration).

\section{Data analysis}

Both $t$ tests and $\chi^{2}$ tests were used to investigate differences in demographic and epilepsy variables between the different epilepsy subgroups (TLE vs. extra-TLE, anteromesial TLE vs. laterobasal TLE, left vs. right, inpatients vs. outpatients). Analysis of covariance (ANCOVA) was performed (correcting for age and sex) to investigate differences between the epilepsy subgroups on the psychological tests that yield continuous data and a logistic regression analysis (with forced entry) for the categoric data of the CIDI. To compensate for multiple testing, a significance level of $p<0.01$ was used.

Linear multiple regression (with forced entry) and logistic regression (with forced entry) analyses were used to explore the association of the different psychological measures with epilepsy-related variables (age at onset, duration of epilepsy, number of AEDs, and seizure frequency).

\section{RESULTS}

\section{Subjects}

The patients in the TLE group had a higher proportion of females $\left(\chi^{2}=8.356 ; d f=1 ; \mathrm{p}<0.01\right)$, were older $[t(129)=2.618 ; \mathrm{p}<0.01]$, had a longer duration 
TABLE 5. Mean depression scores (BDI) and prevalence rates of mood disorders (CIDI) for the TLE and extra-TLE patients

\begin{tabular}{lccc}
\hline Instruments & TLE & Extra-TLE & $\mathrm{p}$ \\
\hline BDI & $\mathrm{n}=63$ & $\mathrm{n}=63$ & $\mathrm{NS}$ \\
Mean (corrected) total score (SD) & $9.82(8.46)$ & $10.55(8.68)$ & \\
CIDI (last year) (\%) & $\mathrm{n}=66$ & $\mathrm{n}=64$ & $\mathrm{NS}$ \\
$\quad$ Major depression & 21.2 & 21.9 & \\
Dysthymia & 6.1 & 3.1 & \\
Mood disorders total & 21.2 & 23.4 & \\
\hline
\end{tabular}

For the BDI: ANCOVA with Group and Sex as fixed factors, Age as covariate. For the CIDI: logistic regression analysis (correcting for sex and age).

TLE, Temporal lobe epilepsy; SD, standard deviation; NS, not significant.

of epilepsy $[t(119)=2.615 ; \mathrm{p}<0.01]$, and had fewer seizures $\left(\chi^{2}=22.590 ; d f=3 ; \mathrm{p}<0.001\right)$ compared with the extra-TLE patients. No differences in patient characteristics were found between patients with anteromesial TLE and laterobasal TLE.

The patients with a lateralization of the epilepsy in the left hemisphere were not different from the righthemisphere group on demographic and epilepsy characteristics, except for seizure frequency $\left(\chi^{2}=9.535 ; d f=\right.$ $3 ; p<0.05)$ (patients in the left group had fewer seizures).

Inpatients differed from outpatients in that they had more seizures $\left(\chi^{2}=11.066 ; d f=3 ; \mathrm{p}<0.05\right)$ and they used more AEDs $[t(129)=3.699 ; \mathrm{p}<0.001]$.

\section{Depression}

In Table 5, mean depression scores on the BDI and prevalence rates of DSM-IV mood disorders are shown for the TLE and extra-TLE patients.

No differences on depression were found between TLE and extra-TLE patients. Similarly, no differences were found between patients with a lateralization of the epilepsy in the left and right hemispheres, and anteromesial TLE and laterobasal TLE.

\section{Anxiety}

Anxiety scores on the ZBV and the prevalence of anxiety disorders according to the DSM-IV in patients with TLE and extra-TLE are shown in Table 6.

No differences on anxiety measures were found between TLE and extra-TLE patients, either between the left and right patient group, or between patients with anteromesial TLE and laterobasal TLE.

\section{Personality}

The results of the VKP and the NEO-FFI are displayed in Table 7. Again, no differences between the various subgroups (TLE vs. extra-TLE, left vs. right, anteromesial TLE vs. laterobasal TLE) were found on any personality subscale.
TABLE 6. Mean anxiety scores $(\mathrm{ZBV})$ and prevalence rates of anxiety disorders (CIDI) for the TLE and extra-TLE patients

\begin{tabular}{lccc}
\hline Instruments & TLE & Extra-TLE & $\mathrm{p}$ \\
\hline ZBV [corrected means (SD)] & $\mathrm{n}=67$ & $\mathrm{n}=62$ & $\mathrm{NS}$ \\
$\quad$ Anxiety state & $38.48(10.05)$ & $34.83(10.29)$ & \\
Anxiety trait & $42.60(12.22)$ & $39.65(12.51)$ & \\
CIDI (last year) (\%) & $\mathrm{n}=66$ & $\mathrm{n}=64$ & $\mathrm{NS}$ \\
Panic disorder & 7.6 & 3.1 & \\
General anxiety disorder & 6.1 & 7.8 & \\
Agoraphobia & 1.5 & 1.6 & \\
Social phobia & 6.1 & 10.9 & \\
Simple phobia & 4.5 & 12.7 & \\
Obsessive-compulsive disorder & 0 & 0 & \\
Anxiety disorders total & 15.2 & 21.9 & \\
\hline
\end{tabular}

For the ZBV: ANCOVA with Group and Sex as fixed factors, Age as covariate. For the CIDI: logistic regression analysis (correcting for sex and age).

TLE, Temporal lobe epilepsy; SD, standard deviation; NS, not significant.

\section{General psychopathology}

In Table 8, the results of the SCL-90 and HADS are shown. No differences were found between TLE and extraTLE, either between left and right hemisphere, or between anteromesial TLE and laterobasal TLE.

\section{Psychological dissociation}

The results of the DIS.Q are shown in Table 9. Again, no differences between the various subgroups were found.

TABLE 7. Mean scores on the VKP and NEO-FFI for the TLE and extra-TLE patients

\begin{tabular}{lccc}
\hline Instruments & TLE & Extra-TLE & $\mathrm{p}$ \\
\hline VKP traits [corrected means (SD)] & $\mathrm{n}=62$ & $\mathrm{n}=61$ & $\mathrm{NS}$ \\
$\quad$ & $1.88(1.69)$ & $1.75(1.75)$ & \\
Paranoid & $1.40(1.28)$ & $1.08(1.32)$ & \\
Schizoid & $1.47(1.57)$ & $1.59(1.62)$ & \\
Schizotypical & $1.05(2.02)$ & $1.78(2.09)$ & \\
Antisocial & $1.71(1.81)$ & $1.95(1.87)$ & \\
Borderline & $1.36(1.47)$ & $1.22(1.52)$ & \\
Histrionic & $1.07(1.57)$ & $1.47(1.62)$ & \\
Narcissistic & $2.14(2.01)$ & $1.80(2.07)$ & \\
Avoidant & $2.03(2.06)$ & $1.85(2.12)$ & \\
Dependent & $2.02(1.74)$ & $1.89(1.79)$ & \\
Obsessive-compulsive & $1.00(1.28)$ & $1.24(1.33)$ & \\
Passive-aggressive & $1.83(1.67)$ & $1.47(1.73)$ & \\
Depressive & $17.97(13.69)$ & $17.52(14.11)$ & \\
Total & $\mathrm{n}=60$ & $\mathrm{n}=60$ & $\mathrm{NS}$ \\
NEO-FFI [corrected means (SD)] & $35.88(8.74)$ & $32.35(8.95)$ & \\
Neuroticism & $37.20(6.52)$ & $39.77(6.68)$ & \\
Extraversion & $34.55(6.11)$ & $37.40(6.26)$ & \\
Openness & $43.35(4.98)$ & $43.73(5.10)$ & \\
Agreeableness & $43.60(6.40)$ & $44.73(6.55)$ & \\
Conscientiousness & & & \\
\hline
\end{tabular}

ANCOVA with Group and Sex as fixed factors, Age as covariate.

TLE, Temporal lobe epilepsy; SD, standard deviation; NS, not significant. 
TABLE 8. Mean scores on the SCL-90 and HADS subscales for the TLE and extra-TLE patients

\begin{tabular}{lccc}
\hline Instruments & TLE & Extra-TLE & $\mathrm{p}$ \\
\hline SCL-90 [corrected means (SD)] & $\mathrm{n}=63$ & $\mathrm{n}=62$ & $\mathrm{NS}$ \\
Anxiety & $16.29(6.64)$ & $16.23(6.73)$ & \\
Agoraphobia & $9.09(3.64)$ & $9.80(3.69)$ & \\
Depression & $27.18(9.60)$ & $27.07(9.76)$ & \\
Somatic complaints & $19.26(6.75)$ & $19.12(6.85)$ & \\
Insufficiency & $17.81(7.21)$ & $17.70(7.32)$ & \\
Sensitivity & $28.06(10.49)$ & $28.42(10.65)$ & \\
Hostility & $8.07(2.87)$ & $8.42(2.91)$ & \\
Sleeping problems & $5.66(2.75)$ & $5.56(2.80)$ & \\
Psychoneuroticism (total score) & $144.48(42.54)$ & $145.17(43.18)$ & \\
HADS [corrected means (SD)] & $\mathrm{n}=41$ & $\mathrm{n}=51$ & $\mathrm{NS}$ \\
Anxiety & $6.30(4.07)$ & $5.60(4.51)$ & \\
Depression & $4.61(3.60)$ & $4.53(3.98)$ & \\
Total & $10.91(6.76)$ & $10.13(7.48)$ & \\
\hline
\end{tabular}

ANCOVA with Group and Sex as fixed factors, Age as covariate.

TLE, Temporal lobe epilepsy; SD, standard deviation; NS, not significant.

\section{Inpatients versus outpatients}

For all the psychological inventories, we also compared the results of inpatients with those of outpatients. No differences between these subgroups were found.

\section{Potential risk factors}

No associations were found between the prevalence of mood and anxiety disorders with the epilepsy-related variables "age at onset," "duration of epilepsy," "seizure frequency," and "number of AEDs." The results of the linear multiple regression analyses, in which the association of the psychological measures (with continuous data) with epilepsy-related variables was explored, are shown in Table 10. Several associations were found, especially with the variables "duration of epilepsy" and "seizure frequency." No associations were found for the HADS and DIS.Q total scores. These findings show no specific preference for an association of these epilepsy-related variables with more state- or trait-oriented measures of psychopathology.

TABLE 9. Mean scores on the DIS.Q subscales for the TLE and extra-TLE patients

\begin{tabular}{lccc}
\hline Instruments & TLE & Extra-TLE & $\mathrm{p}$ \\
\hline DIS.Q [corrected means (SD)] & $\mathrm{n}=60$ & $\mathrm{n}=59$ & $\mathrm{NS}$ \\
Identity confusion/fragmentation & $1.43(0.49)$ & $1.48(0.50)$ & \\
Loss of control & $1.72(0.51)$ & $1.71(0.52)$ & \\
Amnesia & $1.62(0.59)$ & $1.67(0.60)$ & \\
Absorption & $2.06(0.78)$ & $2.16(0.80)$ & \\
Total score & $1.61(0.47)$ & $1.65(0.48)$ & \\
\hline
\end{tabular}

ANCOVA with Group and Sex as fixed factors, Age as covariant.

TLE, Temporal lobe epilepsy; SD, standard deviation; NS, not significant.

\section{Summary}

Because of the multitude of data, Table 11 provides a summary of the findings.

\section{DISCUSSION}

Our study assessed psychiatric comorbidity and personality characteristics in patients with partial epilepsy. The majority of these patients were difficult to treat. Some patients were admitted for presurgical evaluation. However, overall the study population consisted of a broad selection of "regular" epilepsy patients in an epilepsy center, not a highly selected subgroup of surgical candidates. Strict criteria were applied for the psychiatric diagnosis, and a comprehensive psychological assessment was performed in which symptoms of interictal depression, anxiety, personality traits, and psychological dissociation were determined. Contrary to many previous studies, however, our patients were diagnosed according to the localizationrelated concept of the 1989 ILAE Classification of Epilepsies and Epileptic Syndromes, and the localization and lateralization of the epileptogenic zone was established for each patient by using the clinical criteria for (preliminary) noninvasive presurgical evaluation, including ictal videoEEG monitoring in slightly $>50 \%$ of the cases. For a nonselected epilepsy population, this is quite exceptional, and because also in other cases, the localizing diagnosis was made with a "surgically oriented" approach, our series compares favorably with many of the previous published studies (Tables 1 and 2).

In this relatively large group of clinically distinct and identified patients, the popular hypothesis that patients with TLE will show more psychiatric symptoms, compared with extra-TLE patients, could not be confirmed. Our data also do not show the expected overrepresentation of psychiatric symptoms, notably, depressive symptoms, in epilepsy patients for whom temporomesial limbic structures are supposed to be most prominently involved. Of course, these findings should be interpreted with caution. Although the TLE and extra-TLE groups are reasonably large, the specific TLE patient subgroups were relatively small (26 patients in each TLE subgroup), which makes it difficult to find significant differences (assuming that these differences exist). Moreover, the localization-related syndrome was established by using noninvasive criteria only, which leaves room for uncertainty. Nevertheless, our diagnostic criteria compare favorably with those in most of the studies claiming to find more psychopathology or personality disorders in TLE (Table 1), which moreover tend to compare the TLE subjects with other nonepilepsy subjects or generalized epilepsy patients with no extraTLE. In Table 2, showing studies failing to find more psychopathology or personality disorders in TLE, a number of 
TABLE 10. Multiple regression (forced entry) with significant regression coefficients (betas) and squared multiple correlations $\left(R^{2}\right)$ with the psychological tests as dependent variables and the epilepsy-related variables as independent variables

\begin{tabular}{|c|c|c|c|c|c|}
\hline \multirow[b]{2}{*}{ Psychological measures } & \multicolumn{5}{|c|}{ Epilepsy-related variables } \\
\hline & Age at onset of epilepsy & Duration of epilepsy & Seizure frequency & Number of AEDs & $R^{2}$ \\
\hline BDI total score & & & 0.23 & & 0.14 \\
\hline \multicolumn{6}{|l|}{$Z B V$} \\
\hline Anxiety state & & -0.28 & & & 0.07 \\
\hline Anxiety trait & & -0.33 & & & 0.10 \\
\hline \multicolumn{6}{|l|}{$V K P$} \\
\hline Paranoid & -0.31 & -0.25 & & & 0.15 \\
\hline Schizoid & & 0.32 & & & 0.12 \\
\hline \multicolumn{6}{|l|}{ Schizotypical } \\
\hline Antisocial & -0.26 & -0.24 & 0.21 & & 0.12 \\
\hline Borderline & & & 0.21 & & 0.09 \\
\hline Histrionic & & & & 0.24 & 0.12 \\
\hline Narcissistic & & & & 0.25 & 0.13 \\
\hline Avoidant & & & & 0.23 & 0.08 \\
\hline \multicolumn{6}{|l|}{ Dependent } \\
\hline OCD & & & 0.26 & 0.27 & 0.15 \\
\hline Passive-aggressive & & & 0.20 & & 0.11 \\
\hline \multicolumn{6}{|l|}{ Depressive } \\
\hline \multicolumn{6}{|l|}{$N E O$} \\
\hline Neuroticism & & -0.33 & & & 0.09 \\
\hline \multicolumn{6}{|l|}{ Extraversion } \\
\hline \multicolumn{6}{|l|}{ Openness } \\
\hline Agreeableness & & & & -0.28 & 0.11 \\
\hline \multicolumn{6}{|l|}{ Conscientiousness } \\
\hline \multicolumn{6}{|l|}{$S C L-90$} \\
\hline \multicolumn{6}{|l|}{ Anxiety } \\
\hline \multicolumn{6}{|l|}{ Agoraphobia } \\
\hline Depression & & -0.28 & 0.25 & & 0.14 \\
\hline Somatic complaints & & -0.24 & 0.21 & & 0.11 \\
\hline Insufficiency & & -0.25 & & & 0.07 \\
\hline Sensitivity & & & & & \\
\hline Hostility & -0.30 & -0.32 & & & 0.12 \\
\hline Sleeping problems & & & & & \\
\hline Total score (psychoneuroticism) & & -0.29 & & & 0.11 \\
\hline
\end{tabular}

studies did indeed compare TLE with extra-TLE partialseizure patients. Many of the more recent studies did use noninvasive or even invasive presurgical localizing criteria comparable to ours. This suggests that our "negative" findings are indeed relevant and indicate no gross differences between TLE and extra-TLE regarding parameters of psychopathology.

An often-cited cause of the supposed excess of psychopathology in TLE is the claimed excessive involvement of the limbic system in (mesial) TLE. It has been

TABLE 11. Summary of the study results

\begin{tabular}{lc}
\hline Psychopathology & Results \\
\hline $\begin{array}{l}\text { Depression, anxiety, general } \\
\text { psychopathology, personality, } \\
\text { psychological dissociation }\end{array}$ & $\begin{array}{c}\text { No differences were found } \\
\text { between TLE and extra-TLE; } \\
\text { anteromesial TLE and } \\
\text { laterobasal TLE; left and right; } \\
\text { or inpatients and outpatients } \\
\text { A higher level of psychiatric } \\
\text { disturbances in patients with } \\
\text { more seizures and a shorter } \\
\text { duration of the seizure disorder }\end{array}$ \\
\end{tabular}

suggested that limbic activation during seizures is associated with interictal psychopathology, because repeated seizure involvement of limbic tissue may lead to kindlinglike processes that can alter limbic function interictally (Robertson, 1998). However, only a minority of patients with TLE develop significant psychopathology, and the extensive limbic involvement in extra-TLE seizures, notably those originating in the anterior cingular region of the frontal lobe, has by now been well established. This suggests that the supposed change in limbic functioning may not directly cause pathology but rather may increase the vulnerability to psychological problems (Adamec, 1990; Ring and Way, 1991).

Our results of the analyses of other potential (epilepsyrelated) risk factors showed that especially the duration of epilepsy and seizure frequency were frequently associated with psychiatric symptoms. In general we found that patients with more seizures and a shorter duration of their seizure disorder showed more psychiatric problems. So it seems that coping and adjusting to a new medical problem is difficult for the patient, especially in the short term and when seizures are poorly controlled. 
Another assumption concerns the role of concomitant frontal lobe dysfunction in the association between (left) TLE and psychopathology. Functional imaging techniques have shed some light on the possible link with frontal lobe dysfunction and hypometabolism. By using the PET scan, Bromfield et al. (1992) found more depressive symptoms in patients with left temporal foci and hypometabolism in the inferior frontal lobes bilaterally. Some years later, Schmitz et al. (1997) confirmed these findings with SPECT. Hermann et al. (1991) also hypothesized that an association exists between depression and frontal lobe dysfunction that partly explains the previous conflicting results of depression and left-TLE relations. So variations in the intactness of frontal lobe function may also be considered as a potential (additional) risk factor for interictal psychopathology in epilepsy and should be studied in the future.

Aside from the negative findings with regard to the localization of the epilepsy syndrome, we found no difference between patients with lateralization of epilepsy in the left versus right hemisphere and between inpatients and outpatients. Notably, the comparable level of psychopathology of both inpatients and outpatients was surprising because more psychiatric problems were expected in the inpatient subgroup, related to their more severe epilepsy (i.e., more seizures and more AEDs). These results, again, support the theory that probably other (nonbrain-related) factors are involved in the development of psychiatric symptoms in patients with epilepsy.

As for the total level of psychopathology, we found fairly comparable levels of mood and anxiety disorders as found in a previous study (Swinkels et al., 2001). The prevalence of both mood and anxiety disorders is higher than what is generally found in the general population. The same applies to the personality traits. However, in comparison with our previous investigation (Swinkels et al., 2003), more personality disorder traits were found in these specific subgroups of epilepsy patients.

In summary, epilepsy carries with it an increased risk for developing interictal psychiatric disturbances. It is assumed that the risk is higher for patients with partial epilepsy in comparison with patients with idiopathic generalized epilepsy. Besides, the chronicity (i.e., psychosocial impact of epilepsy) of the medical condition seems to be an important factor for this increased risk (Swinkels et al., 2005).

Despite the quite large patient groups, strict diagnostic criteria applied to present-day epilepsy diagnosis, and the wide variety of diagnostic instruments (both rating scales and objective and standardized diagnostic instruments) that were used for the assessment of depression, anxiety, personality, and dissociative symptoms, our findings consistently yielded no evidence for associations between the different parameters of psychopathology and the localization and lateralization of the epilepsy syndromes. This applies to both subjective self-reports and the more objective interviews. Nevertheless, one should bear in mind that some of the instruments that were used in this study possibly reflect the same constructs.

Moreover, our findings do not correspond with the cited studies in which more outdated methods of epilepsy classification were used but are more in accordance with studies whereby a more recent and sound method of epilepsy classification and localization is used.

It seems, therefore, that temporal lobe epilepsy per se cannot be considered a higher-risk condition for developing different psychiatric problems. Concomitant factors, such as duration of the epilepsy, seizure frequency, and frontal lobe dysfunction may play an important role. Our findings support the hypothesis of a multifactorial explanation for the psychiatric symptoms in patients with epilepsy. Despite the growing evidence that several factors may contribute to psychiatric disorders in epilepsy, these factors are frequently not controlled for in studies of epilepsy and psychopathology. Apart from these (brain-related) epilepsy factors, the psychosocial impact of having a chronic epileptic condition (e.g., unemployment, stigmatization) should also not be underestimated and should be more integrated in future studies on psychopathology. Continued investigation of these factors, therefore, is certainly recommended.

Acknowledgment: This study was sponsored by De Christelijke Vereniging voor de Verpleging van Lijders aan Epilepsie, Heemstede, The Netherlands (Teding van Berkhout Fellowship).

We thank A. Tierlier-Long for manuscript preparation.

\section{REFERENCES}

Adamec RE. (1990) Does kindling model anything clinically relevant? Biology and Psychiatry 27:249-279.

Altshuler LL, Devinsky O, Post RM, Theodore W. (1990) Depression, anxiety, and temporal lobe epilepsy. Archives of Neurology 47:284 288.

Arrindell WA, Ettema JHM. (1986) Handleiding SCL-90. Swets \& Zeitlinger, Lisse.

Bear DM, Fedio P. (1977) Quantitative analysis of interictal behavior in temporal lobe epilepsy. Archives of Neurology 34:454-467.

Beck AT, Rush AJ, Shaw BF, Emery G. (1979) Cognitive therapy of depression. Wiley \& Sons, New York.

Betts TA. (1981) Depression, anxiety and epilepsy. In Reynolds EH, Trimble MR (Eds) Epilepsy and psychiatry. Churchill Livingstone, Edinburgh, pp. 60-71.

Bouman TK, Luteijn F, Albersnagel FA, Van der Ploeg FAE. (1985) Enige ervaringen met de Beck Depression Inventory (BDI). Gedrag - Tijdschrift voor Psychologie 13:13-24.

Bromfield EB, Altshuler L, Leiderman DB, Balish M, Ketter TA, Devinsky O, Post RM, Theodore WH. (1992) Cerebral metabolism and depression in patients with complex partial seizures. Archives of Neurology 49:617-623.

Brown SW, McGowan MEL, Reynolds EH. (1986) Influence of seizure type and medication on psychiatric symptoms in epileptic patients. British Journal of Psychiatry 148:300-304.

Commission on Classification and Terminology of the International League Against Epilepsy. (1981) Proposal for revised clinical and electroencephalographic classification of epileptic seizures. Epilepsia 22:489-501. 
Commission on Classification and Terminology of the International League Against Epilepsy. (1989) Proposal for revised classification of epilepsies and epileptic syndromes. Epilepsia 30:389-399.

Composite International Diagnostic Interview (CIDI). (1993) World Health Organization, Geneva.

Costa PT, McCrae RR. (1992) Revised NEO Personality Inventory (NEO$P I-R)$ and the Five Factor Inventory (NEO-FFI): professional manual. Psychological Assessment Resources Inc, Odessa, Florida.

Derogatis LR. (1977) SCL-90: administration, scoring and procedures manual for the Revised Version. John Hopkins University School of Medicine, clinical psychometrics research unit, Baltimore.

Dikmen S, Hermann BP, Wilensky AJ, Rainwater G. (1983) Validity of the Minnesota Multiphasic Personality Inventory (MMPI) to psychopathology in patients with epilepsy. Journal of Nervous and Mental Disease 171:114-122.

Dodrill CB, Batzel LW. (1986) Interictal behavioural features of patients with epilepsy. Epilepsia 27(suppl 2):S64-S76.

Drevets WC, Videen TO, Price JL, Preskorn SH, Carmichael ST, Raichle ME. (1992) A functional anatomical study of unipolar depression. Journal of Neuroscience 12:3628-3641.

Duijsens IJ, Haringsma R, Eurelings-Bontekoe EHM. (1999) De VKP handleiding, DSM-IV \& ICD-10. Datec, Leiderdorp, The Netherlands.

Edeh J, Toone B. (1987) Relationship between interictal psychopathology and the type of epilepsy. British Journal of Psychiatry 151:95101 .

Emde Boas W van, Parra Gomez J. (2001) Long term non-invasive EEG/video monitoring in temporal lobe epilepsy. In Luders HO, Comair Y (Eds) Epilepsy surgery. 2nd ed. Lippincott Williams \& Wilkins, Philadelphia, pp 413-429.

Ettinger AB, Weisbrot DM, Krupp LB, Jandorf L, Gaudino E, Cramer J. (1998) Symptoms of psychiatric disturbance in epilepsy. Journal of Epilepsy 11:10-14.

Feddersen B, Herzer R, Hartmann U, Gaab MR, Runge U. (2005) On the psychopathology of unilateral temporal lobe epilepsy. Epilepsy \& Behavior 6:43-49.

Fiordelli E, Beghi E, Graziella B, Crespi V. (1993) Epilepsy and psychiatric disturbance. British Journal of Psychiatry 63:446-450.

Flor-Henry P. (1969) Psychosis and temporal lobe epilepsy. Epilepsia 10:363-395.

Gibbs FA, Gibbs EL, Furster B. (1948) Psychomotor epilepsy. Archives of Neurology and Psychiatry 60:331-339.

Gibbs FA. (1951) Ictal and non-ictal psychiatric disorders in temporal lobe epilepsy. Journal of Nervous and Mental Disease 11:522-528.

Grasso MG, Pantano P, Ricci M, Pace A, Pandovani A, Orzi F, Pozzilli C, Lenzi GL. (1994) Mesial temporal cortex hypoperfusion is associated with depression in subcortical stroke. Stroke 25:980-985.

Gudmundsson G. (1966) Epilepsy in Iceland. Acta Neurologica Scandinavica 43(suppl 25):1-124.

Guerrant J, Anderson WW, Fischer A, Weinstein MR, Jaros RM, Deskins A. (1962) Personality in epilepsy. Charles C Thomas, Springfield, Ill.

Gureje O. (1991) Interictal psychopathology in epilepsy: prevalence and pattern in a Nigerian clinic. British Journal of Psychiatry 158:700705 .

Helmstaedter C, Sonntag-Dillender M, Hoppe C, Elger CE. (2004) Depressed mood and memory impairment in temporal lobe epilepsy as a function of focus lateralisation and localisation. Epilepsy \& Behavior 5:696-701.

Hermann BP, Whitman S. (1984) Behavioral and personality correlates of epilepsy: a review, methodological critique, and conceptual model. Psychology Bulletin 95:451-497.

Hermann BP, Wyler AR. (1989) Depression, locus of control, and the effects of epilepsy surgery. Epilepsia 30:332-338.

Hermann BP, Seidenberg M, Haltiner A, Wyler AR. (1991) Mood state in unilateral temporal lobe epilepsy. Biology and Psychiatry 30:12051218.

Hermann BP, Seidenberg M, Bell B. (2000) Psychiatric comorbidity in chronic epilepsy: Identification, consequences, and treatment of major depression. Epilepsia 41(suppl 2):S31-S41.

Hoekstra HA, Ormel J, De Fruyt F. (1996) NEO PI-R and NEO-FFI. Big Five Persoonlijkheidsvragenlijsten. Swets \& Zeitlinger, Handleiding, Lisse.
Isaacs KL, Philbeck JW, Barr WB, Devinsky O, Alper K. (2004) Obsessive-compulsive symptoms in patients with temporal lobe epilepsy. Epilepsy \& Behavior 5:569-574.

Jalava M, Sillanpaa M. (1996) Concurrent illnesses in adults with childhood-onset epilepsy: a population-based 35-year follow-up study. Epilepsia 37:1155-1163.

Kogeorgos J, Fonagy P, Scott DF. (1982) Psychiatric symptom patterns of chronic epileptics attending a neurological clinic: a controlled investigation. British Journal of Psychiatry 140:236-243.

Kohler C, Norstrand JA, Baltuch G, O'Connor MJ, Gur RE, French JA, Sperling MR. (1999) Depression in temporal lobe epilepsy before epilepsy surgery. Epilepsia 40:336-340.

Kuyk J, Spinhoven Ph, Van Emde Boas W, Van Dyck R. (1999) Dissociation in temporal lobe epilepsy and pseudo-epileptic seizure patients. Journal of Nervous and Mental Disease 187:713-720.

Maillard L, Vignal JP, Gavaret M, Guye M, Biraben A, McGonigal A, Chauvel P, Bartolomei F. (2004) Semiologic and electrophysiological correlations in temporal lobe seizure subtypes. Epilepsia 45:1590-1599.

Manchanda R, Schaefer B, McLachlan RS, Blume WT. (1995) Interictal psychiatric morbidity and focus of epilepsy in treatment-refractory patients admitted to an epilepsy unit. American Journal of Psychiatry 149:1096-1098.

Manchanda R, Schaefer B, McLachlan RS, Blume WT. (1995) Relationship of site of seizure focus to psychiatric morbidity. Journal of Epilepsy 8:23-28.

Matthews CG, Klove H. (1968) MMPI performances in major motor, psychomotor and mixed seizure classifications of known and unknown etiology. Epilepsia 9:43-53.

Mendez MF, Cummings JF, Benson DF. (1986) Depression in epilepsy: significance and phenomenology. Archives of Neurology 43:766770.

Mendez MF, Taylor JL, Doss RC, Salguero P. (1994) Depression in secondary epilepsy: relation to lesion laterality. Journal of Neurology, Neurosurgery and Psychiatry 57:232-233.

Mignone RJ, Donnelly EF, Sadowsky D. (1970) Psychological and neurological comparisons of psychomotor and non-psychomotor epileptic patients. Epilepsia 11:345-359.

Naugle RI, Rodgers DA, Stagno SJ, Lalli J. (1991) Unilateral temporal lobe epilepsy: an examination of psychopathology and psychosocial behavior. Journal of Epilepsy 4:157-164.

Paradiso S, Hermann BP, Robinson RG. (1995) The heterogeneity of temporal lobe epilepsy. Journal of Nervous and Mental Disease 183:538-547.

Perini G, Mendius R. (1984) Depression and anxiety in complex partial seizures. Journal of Nervous and Mental Disease 172:287-290.

Perini GI, Tosin C, Carraro C, Bernasconi G, Canevini MP, Canger MP, Pellegrini A, Testa G. (1996) Interictal mood and personality disorders in temporal lobe epilepsy and juvenile myoclonic epilepsy. Journal of Neurology, Neurosurgery and Psychiatry 61:601605.

Pond DA, Bidwell BH. (1959) A survey of epilepsy in fourteen general practices, II: social and psychological aspects. Epilepsia 1:285299.

Quiske A, Helmstaedter C, Lux S, Elger CE. (2000) Depression in patients with temporal lobe epilepsy is related to mesial temporal sclerosis. Epilepsy Research 39:121-125.

Ring HA, Way R. (1991) Depression in epilepsy: biological links. Biology and Psychiatry 2:215-218.

Robertson MM, Trimble MR. (1983) Depressive illness in patients with epilepsy: a review. Epilepsia 24(suppl 2):S109-S116.

Robertson MM, Trimble MR, Townsend HRA. (1987) Phenomenology of depression in epilepsy. Epilepsia 28:364-372.

Robertson MM. (1998) Mood disorders associated in epilepsy. In McConnel HW, Snyder PJ (Eds) Psychiatric comorbidity in epilepsy. American Psychiatric Press, London.

Rodin EA, Katz M, Lennox K. (1976) Differences between patients with temporal lobe seizures and those with other forms of epileptic attacks. Epilepsia 17:313-320.

Sabatini U, Pozzilli C, Pantano P, Koudiavtseva T, Pandovani A, Millefiorini E, Di Biasi C, Gualdi GF, Salvetti M, Lenzi GL. (1996) Involvement of the limbic system in multiple sclerosis patients with depressive disorders. Biology and Psychiatry 39:970-975. 
Schmitz EB, Moriarty J, Costa J DC, Ring HA, Ell PJ, Trimble MR. (1997) Psychiatric profiles and patterns of cerebral blood flow in focal epilepsy: interactions between depression, obsessionality, and perfusion related to the laterality of the epilepsy. Journal of Neurology, Neurosurgery and Psychiatry 62:458-463.

Schwartz J, Cummings JL. (1988) Psychopathology in epilepsy: an outpatient consultation-liaison experience. Psychosomatics 29:295300.

Septien L, Giroud M, Didi-Roy R. (1993) Depression and partial epilepsy: relevance of laterality of the epileptic focus. Neurology Research 15:136-138.

Shukla GD, Srivastava ON, Katiyar BC, Joshi V, Mohan PK. (1979) Psychiatric manifestations in temporal lobe epilepsy: a controlled study. British Journal of Psychiatry 135:411-417.

Small JG, Milstein V, Stevens JR. (1962) Are psychomotor epileptics different? A controlled study. Archives of Neurology 7:187-194.

Small JG, Small IF, Hayden MP. (1966) Further psychiatric investigations of patients with temporal and nontemporal lobe epilepsy. American Journal of Psychiatry 123:303-310.

Spiegelberger CD, Gorsuch RL, Lushene RE. (1970) Manual for the State-Trait anxiety inventory. (self-evaluation questionnaire). Consulting Psychologists Press, Palo Alto, Calif.

Spinhoven Ph, Ormel J, Sloekers PPA, Kempen GIJM, Specksens AEM, Van Hemert AM. (1997) A validation study of the Hospital Anxiety and Depression Scales (HADS) in different groups of Dutch subjects. Psychological Medicine 27:363-370.

Standage KF, Fenton GW. (1975) Psychiatric symptom profiles of patients with epilepsy: a controlled investigation. Psychological Medicine 5:152-160.

Stevens JR. (1966) Psychiatric implications of psychomotor epilepsy. Archives of General Psychiatry 14:461-471.
Swinkels WAM, Kuyk J, De Graaf EH, Van Dyck R, Spinhoven PH. (2001) Prevalence of psychopathology in Dutch epilepsy patients: a comparative study. Epilepsy \& Behavior 2:441-447.

Swinkels WAM, Duijsens IJ, Spinhoven PH. (2003) Personality disorder traits in patients with epilepsy. Seizure 12:587-594.

Swinkels WAM, Kuyk J, Van Dyck R, Spinhoven PH. (2005) Psychiatric comorbidity in epilepsy. Epilepsy \& Bahavior 7:37-50.

Ter Smitten MH, Smeets RMW, Van den Brink W. (1997) Composite International Diagnostic Interview (CIDI), version 2.1. World Health Organization, Amsterdam.

Vanderlinden J, Van Dyck R, Vandereycken W, Verkes RJ. (1993) The dissociation questionnaire: development and characteristics of a new self-reporting questionnaire. Clinical Psychology and Psychotherapy $1: 21-27$.

Van der Ploeg HM, Defares PB, Spielberger CD. (1980) Handleiding bij de Zelf Beoordelings Vragenlijst, ZBV. Swets \& Zeitlinger, Lisse.

Victoroff JI, Benson DF, Crafton ST, Engel J, Mazziotta JC. (1994) Depression in complex partial seizures. Archives of Neurology 51:155163.

Whitman S, Hermann BP, Gordon AC. (1984) Psychopathology in epilepsy: how great is the risk? Biological Psychiatry 19:213-236.

Wieser HG. (1983) Electroclinical features of the psychomotor seizure: a stereoelectroencephalographic study of ictal symptoms and chronotopographical seizure patterns including clinical effects of intracerebral stimulation. Gustav Fisher, Stuttgart, pp. 1-242.

World Health Organisation. (1995) International Personality Disorder Examination (IPDE) DSM-IV Module: Dutch adaptation (Eds.Duijsens IJ, Eurelings-Bontekoe EHM, Diekstra RFW). Datec, Leiderdorp.

Zielinski JJ. Epidemiology and medical social problems of epilepsy in Warsaw. Warsaw Psychoneurological Institute, Warsaw. 